\title{
The role of long-term mechanical circulatory support in the treatment of end-stage heart failure
}

\author{
Lech Paluszkiewicz ${ }^{1}$, Tomasz Kukulski ${ }^{2}$, Michał Zembala ${ }^{3}$, Jan Gummert ${ }^{1}$, Michiel Morshuis ${ }^{1}$ \\ 'Department of Thoracic and Cardiovascular Surgery, Heart and Diabetes Centre North Rhine-Westphalia, \\ Ruhr University Bochum, Bochum, Germany \\ ${ }^{2}$ Department of Cardiology, Congenital Heart Diseases, and Electrotherapy, Silesian Medical University, \\ Silesian Centre for Heart Diseases, Adults Echo Laboratory, Zabrze, Poland \\ ${ }^{3}$ Department of Cardiac, Vascular and Endovascular Surgery, and Transplantology, Silesian Medical University, \\ Silesian Centre for Heart Diseases, Adults Echo Laboratory, Zabrze, Poland
}

\begin{abstract}
A b stract
Heart failure is a clinical syndrome of multifactorial aetiology with typical symptoms and diverse prevalence depending on the world region, reaching more than $10 \%$ in the population over 70 years of age. The prognosis, in spite of a dynamic improvement in medical therapy, remains poor. The only treatment for these patients is heart transplantation, however, its availability is highly limited because of the shortage of donor organs. Mechanical circulatory support can offer an alternative treatment for this patient cohort. In this review the authors discuss the present indications for, as well as results and complications of different types of long-term mechanical circulatory support. The long-term survival in patients receiving this therapy, in spite of many complication, is much better than in those receiving medical treatment. The use of mechanical circulatory support is an established treatment option for many patients with end-stage heart failure. The most important issue for the cardiologist is to identify patients eligible for this therapy in order to give them a chance for a longer life and better quality of life.
\end{abstract}

Key words: biventricular assist device, heart failure, left ventricular assist device, mechanical circulatory support, right ventricular assist device, total artificial heart

Kardiol Pol 2019; 77, 3: 331-340

\section{INTRODUCTION}

Heart failure (HF) is a clinical syndrome of multifactorial aetiology with typical symptoms and diverse prevalence depending on the region of the world. The prevalence in developed countries is $1 \%-2 \%$ and increases with age to more than $10 \%$ in the population over 70 years old. The prognosis, in spite of a dynamic improvement in medical therapy, remains poor. The 12-month all-cause mortality rates for hospitalised patients reached $17 \%$ in an ESC-HF pilot study [1]. According to ejection fraction HF can be divided into HF with reduced ejection fraction, HF with preserved ejection fraction, and HF with mid-range ejection fraction [2]. A specially dedicated heart insufficiency classification - the Interagency Registry for Mechanically Assisted Circulatory Support (INTERMACS) scale (Table 1) - allows categorisation of patients with end-stage HF according to clinical status and prognosis. All patients qualified for mechanical circulatory support (MCS) are categorised according to the INTERMACS classification. HF is a progressive syndrome leading finally to end-stage HF and death. The only treatment for patients with HF is heart transplantation. Unfortunately, it is only available to a small percentage of patients because of the shortage of donor organs. MCS can be an alternative treatment option for this patient cohort.

\section{TYPES OF LONG-TERM MECHANICAL CIRCULATORY SUPPORT}

The goal of MCS is to move the blood from an insufficient ventricle into the aorta or pulmonary artery to restore the normal cardiac output. Since the first successful use of extracorporeal MCS by De Bakey in 1967, this branch of medicine has markedly improved, and today, together with heart transplantation, it is the most important method of treatment for end-stage HF. During more than 50 years of permanent investigation and

Address for correspondence:

Lech Paluszkiewicz, MD, PhD, Heart and Diabetes Centre North Rhine-Westphalia, Department of Thoracic and Cardiovascular Surgery, Ruhr University Bochum, 32545 Bad Oeynhausen, Georgstr. 11, Germany, tel: +495731 973538, fax: +495731971871, e-mail: Ipaluszkiewicz@hdz-nrw.de

Received: 5.02.2019 Accepted: 5.02.2019 Available as AoP: 6.02.2019

Kardiologia Polska Copyright (c) Polish Cardiac Society 2019 
Table 1. Interagency Registry for Mechanically Assisted Circulatory Support (INTERMACS) stages for classifying patients with advanced heart failure. Modified from [45]

\begin{tabular}{|c|c|c|}
\hline Level & Description & Time frame for definitive intervention \\
\hline 1 & $\begin{array}{l}\text { Patient in cardiogenic shock with critical organ hypoperfusion } \\
\text { "Crash and burn" }\end{array}$ & Needed within hours \\
\hline 2 & $\begin{array}{l}\text { Patient with declining function despite intravenous inotropic support } \\
\text { "Sliding on inotropes" }\end{array}$ & Needed within hours \\
\hline 3 & $\begin{array}{l}\text { Patient in stable status on continuous intravenous inotropic support, } \\
\text { impossible to wean } \\
\text { "Dependent stability" }\end{array}$ & Elective over a few weeks \\
\hline 4 & $\begin{array}{l}\text { Patient with recurrent decompensation of heart failure } \\
\text { "Frequent flyer" }\end{array}$ & Elective over weeks to months \\
\hline 5 & $\begin{array}{l}\text { Patient is staying predominantly at home and is comfortable at rest } \\
\text { "Housebound" }\end{array}$ & Variable, depends upon clinical status \\
\hline 6 & $\begin{array}{l}\text { Patient is comfortable at rest and with activities of daily living and minor } \\
\text { activities outside the home } \\
\text { "Walking wounded" }\end{array}$ & Variable, depends upon clinical status \\
\hline 7 & $\begin{array}{l}\text { Patient is living comfortably with meaningful activity limited to } \\
\text { mild exertion }\end{array}$ & $\begin{array}{l}\text { Transplantation or circulatory support } \\
\text { not currently indicated }\end{array}$ \\
\hline
\end{tabular}

development of the ideal device, many different systems of MCS were invented. Nowadays, only a few of them are still present on the market.

Long-term MCS can be divided according to the site of implantation (extra- and intracorporeal support) as well as the driving force (to pneumatic, in which the blood is moved with pressure difference; and electrical, in which the pump is electrically supplied). Another way to divide long-term MCS is according to the type of generated blood flow (pulsatile-flow vs. continuous-flow devices). Finally, based on the site of support, MCS devices can be divided into left ventricular assist device (LVAD), in which the pump supports the left ventricle, right ventricular assist device (RVAD) supporting the right ventricle, biventricular assist device (BiVAD) supporting both ventricles, and total artificial heart (TAH) whereby the device completely replaces the heart function. The last classification is the most commonly used in daily practice.

LONG-TERM LEFT VENTRICULAR ASSIST DEVICE The left ventricle can be supported by pulsatile-flow, pneumatically driven devices (see BiVADs below) or by continuous-flow assist devices, which are currently the most widely used. The role of pneumatically driven devices in isolated support of the left ventricle is limited to special cases. For this reason, herein we focus on continuous-flow assist devices.

Independently of the type, continuous-flow assist devices consist of some common elements: an inflow cannula that is placed in the apex of the left ventricle and an electrically supplied pump that draws the blood from the left ventricle and moves it through the outflow cannula (also known as the outflow graft) in the ascending aorta. The outflow cannula consists of a sealed woven polyester graft. The blood may flow from the left ventricle, either through the LVAD outflow graft or in a "normal" way, through the aortic valve. The amount of flow through the pump depends greatly upon the degree of the patient's cardiac function and the speed settings of the LVAD. The system is supplied with electrical power from external batteries and delivered through a pump cable that is tunnelled through subdermal abdominal tissue and is exteriorised through a skin wound (Fig. 1). The device can be implanted by median sternotomy or by minimally invasive left lateral thoracotomy [3]. Life-long anticoagulant (warfarin) and antiplatelet therapy is mandatory.

Essentially, there are three leading assist devices available on the market: HeartWare (HVAD, Medtronic), HeartMate II (Abbott), and HeartMate 3 (Abbott).

HVAD is a third-generation centrifugal pump with a weight of $160 \mathrm{~g}$, generating continuous flow (Fig. 2). Its operating rotational speed can be adjusted from 2400 to 3200 rpm. HVAD can be implanted intrapericardially by either median sternotomy or left lateral thoracotomy.

HeartMate II is a second-generation axial pump with a weight of $281 \mathrm{~g}$, also generating continuous flow (Fig. 3). The operating rotational speed can be adjusted between 8000 and $10,000 \mathrm{rpm}$. In contrast to the two other devices, HeartMate II must be implanted extrapericardially within a surgically created pocket. The rotor is mounted on ruby bearings, which are lubricated and cooled by the blood steam. The bearings have shown excellent durability, but in the case of disturbed blood 


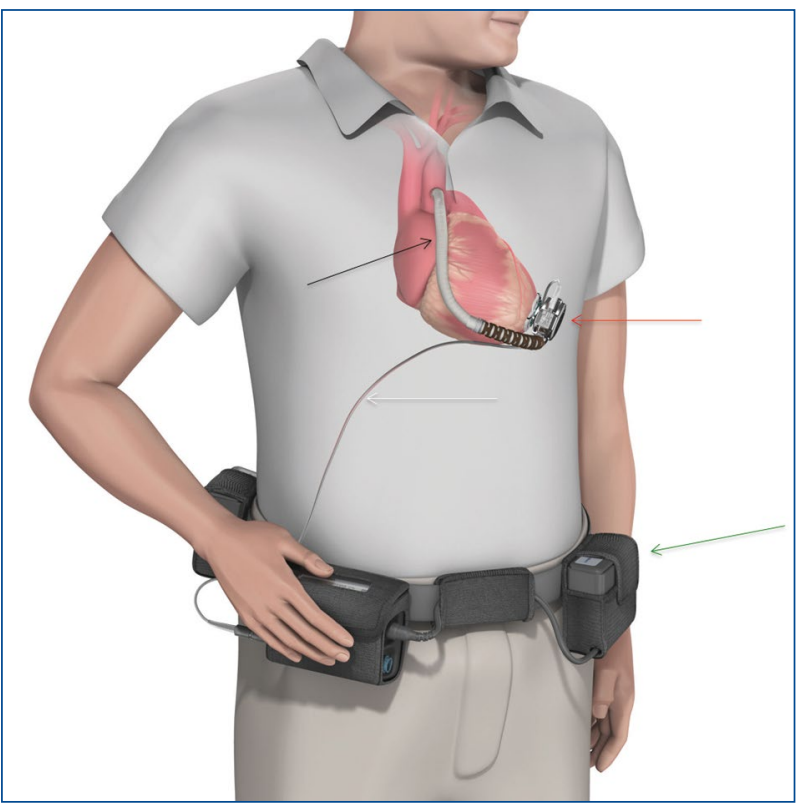

Figure 1. Schematic presentation of continuous flow assist device (HeartWare); red arrow - pump; black arrow - outflow graft; white arrow — pump cable; green arrow — battery (https://www.heartware.com/resources)

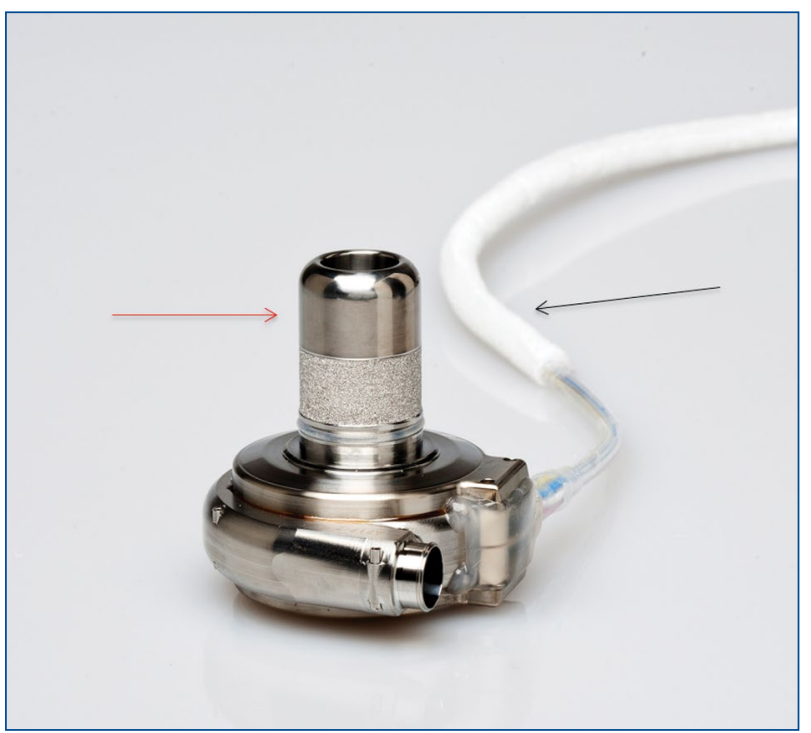

Figure 2. HeartWare continuous flow assist device. The pump with the supply cable; red arrow — inflow cannula, black arrow — pump cable (https://www.heartware.com/resources)

flow, for example in the case of suction, the temperature of the bearing rises rapidly and affects the haemocompatibility, which promotes thrombus formation.

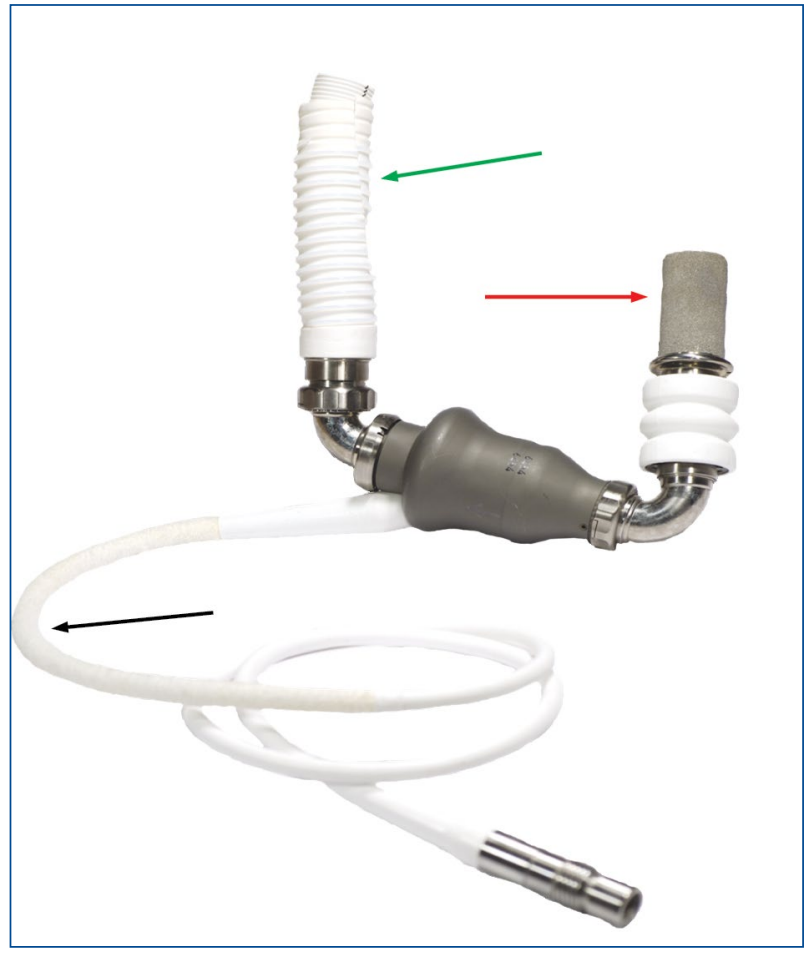

Figure 3. HeartMate II continuous flow assist device. The pump with the supply cable; red arrow - inflow cannula, green arrow — outflow cannula; black arrow — pump cable

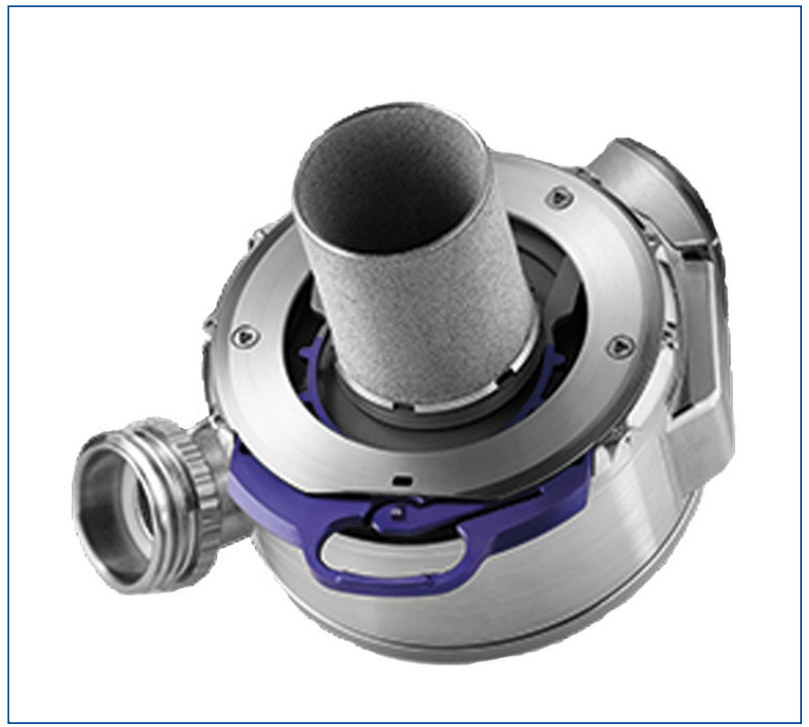

Figure 4. HeartMate 3 continuous flow assist device (https:// www.heartmate.com/sjh/homepage-master/resource-center/ heartmate-3-image)

HeartMate 3 is the most modern third-generation centrifugal system with a weight of $200 \mathrm{~g}$ (Fig. 4). It is the first fully magnetically levitated device with very good control of rotor 
Table 2. Indications for mechanical circulatory support (MCS). Modified from [2]

\begin{tabular}{|ll}
\hline Indication & Description \\
\hline $\begin{array}{l}\text { Bridge-to-decision } \\
\text { Bridge-to-bridge }\end{array}$ & $\begin{array}{l}\text { Patients in cardiogenic shock with unknown neurological status; use of short-term MCS for stabilisation } \\
\text { and verification of neurological status to decide if and which type of support should be used }\end{array}$ \\
Bridge-to-candidacy & $\begin{array}{l}\text { Patients not eligible for transplantation; use of long-term ventricular assist device to improve patient's } \\
\text { status and end organ function }\end{array}$ \\
Bridge-to-transplantation & $\begin{array}{l}\text { Patients with end-stage heart failure waiting for a donor organ, who are at high risk of death } \\
\text { before transplantation }\end{array}$ \\
Bridge-to-recovery & $\begin{array}{l}\text { Patients with end-stage heart failure, in whom recovery of myocardial function could be possible. } \\
\text { Destination therapy }\end{array}$ \\
\hline
\end{tabular}

position in the housing, allowing a greater rotor-to-housing gap. This results in excellent haemocompatibility and a very low rate of pump thrombosis. The operating speed is adjustable between 3000 and $9000 \mathrm{rpm}$; the practically used speed is between 4000 and $6000 \mathrm{rpm}$. HeartMate 3 has a special feature, which makes it unique among the LVADs - the capability to cyclically change the rotor speed to simulate the pulsatile flow and in some ways mimic the native cardiac contractility. This artificial pulse "beat" appears 30 times per minute (from 4000 rpm), asynchronously with the heart rhythm.

There are also other systems available, for instance Incor (BerlinHeart GmbH, Berlin, Germany) or HeartAssist 5 (ReliantHeart Inc., Houston, TX, USA), although now they constitute a relatively small percentage of implantations.

\section{INDICATIONS FOR IMPLANTATION}

\section{OF A LEFT VENTRICULAR ASSIST DEVICE}

The indications for LVAD implantation include different clinical scenarios. The summary is presented in Table 2. Bridge-to-bridge (BTB) and bridge-to-candidacy (BTC) indications refer to the sickest patients who are in cardiogenic shock, unconscious, with unknown neurological status, and frequently after cardiac resuscitation. In order to keep the patient alive until his/her neurological status is clear or end organ function improves giving hope for recovery, a short-term MCS, such as extracorporeal membrane oxygenation or an Impella device, can be used. As a next step, a long-term ventricular assist device (VAD) can be implanted to gain the time needed to evaluate the eligibility for heart transplantation. BTC concerns patients with end-stage HF, who are temporarily ineligible for heart transplantation for various reasons, e.g. neoplastic disease or pulmonary hypertension. To keep them alive, both short- and long-term support can be used, depending on the clinical situation. When causes of ineligibility disappear, the patient may be reconsidered for transplantation. Bridge-to-transplantation (BTT) is the most obvious indication to use VAD and refers to patients who deteriorate while waiting for a donor organ. Mechanical support allows them to survive until the transplantation and prevents end organ damage and clinical deterioration. The first successful use of VAD in men performed by De Bakey was in fact a bridge-to-recovery (BTR). This indication concerns patients who are supposed to recover under mechanical support. Short-term as well as long-term support can be used. There are no clear criteria allowing to predict which patient will recover; therefore, BTR can turn into BTT or destination therapy. The latter refers to patients who are not candidates for heart transplantation for a variety of reasons, for instance due to advanced age or comorbidities. The number of patients being implanted with a device as the destination therapy is increasing rapidly. Between the years 2008 and 2011, destination therapy was an indication for LVAD implantation in the United States in $28.6 \%$ of patients, reaching $49.8 \%$ in the years 2015-2016 [4, 5].

The European Society of Cardiology guidelines on the treatment of acute and chronic HF describe the eligibility criteria for LVAD implantation. According to the guidelines, this procedure should be considered in two clinical settings. The first concerns patients with end-stage HF, who are symptomatic despite optimal medical and device therapy and are eligible for heart transplantation as BTT (class Ila of recommendation). The second involves patients in a similar condition, who are not eligible for transplantation. Implantation of an LVAD should also be considered as destination therapy (class Ila of recommendation) [2]. Furthermore, the guidelines describe the optimal clinical condition of patients eligible for LVAD implantation (Table 3).

\section{COMPLICATIONS}

The overall rate of complications increases with the time of support, independently of the type of the system [5]. The most frequent complications observed after LVAD implantation are stroke, bleeding, infection, right heart failure (RHF), device thrombosis, and device malfunction.

\section{Stroke}

Stroke is one of the most disabling complications occurring after LVAD implantation. Its incidence varies from about $10 \%$ 
Table 3. Patients potentially eligible for implantation of a left ventricular assist device. Adapted from [2]

Patients with over two months of severe symptoms despite optimal medical and device therapy and more than one of the following:

- LVEF $<25 \%$ and, if measured, peak $\mathrm{VO}_{2}<12 \mathrm{~mL} / \mathrm{kg} / \mathrm{min}$

- $\geq$ three HF hospitalisations in the previous 12 months without an obvious precipitating cause

- Dependence on intravenous inotropic therapy

- Progressive end organ dysfunction (worsening renal and/or hepatic pressure [PCWP $\geq 20 \mathrm{mmHg}$ and SBP $\leq 80-90 \mathrm{mmHg}$ or Cl $\left.\leq 2 \mathrm{~L} / \mathrm{min} / \mathrm{m}^{2}\right]$ )

- Absence of severe right ventricular dysfunction together with severe tricuspid regurgitation

$\mathrm{Cl}$ — cardiac index; HF — heart failure; LVEF — left ventricular ejection fraction; PCWP — pulmonary capillary wedge pressure; SBP — systolic blood pressure; $\mathrm{VO}_{2}$ - oxygen consumption

to $20 \%$. Also, it is responsible for increased rates of mortality and hospital readmission [6,7]. The overall incidence of stroke remains high, in spite of the technological progress. In the early era of LVAD the frequency of stroke was as high as 0.22 events per patient-year (EPPY) in patients supported with the HeartMate XVE device. The use of a HeartMate II axial pump was associated with $0.13 \mathrm{EPPY}$, and in patients after implantation of a HeartWare device, 0.27 EPPY was observed [8, 9]. Both ischaemic and haemorrhagic stroke occur with similar frequency; however, the mortality of patients after haemorrhagic stroke was reported to be as high as $70 \%$ after one year of support, as compared to $45 \%$ in patients after ischaemic stroke. Acharya et al. [10] presented data from a registry including 7112 patients supported with continuous-flow LVADs. Stroke occurred in 875 (10.57\%) patients over 35 months of follow-up. In multivariable analysis only female sex and history of previous cardiac surgery were significant predictors of ischaemic stroke. For haemorrhagic stroke, the only significant predictors were female sex, use of intra-aortic balloon counterpulsation, and heparin-induced thrombocytopaenia. Interestingly, history of stroke or atrial fibrillation was not associated with increased risk of stroke after implantation. Postoperative bleeding and infection significantly increased the risk of stroke [10]. The mechanisms leading to stroke under LVAD support are not clear. Mechanical support leads to an aberrant haemocompatible physiological state due to contact between the patient's blood and the interior surface of the device, additionally intensified by a high rotor speed. The increased shear stress contributes, among others, to haemolysis, platelet activation, and the loss of high-molecular-weight multimers of von Willebrand factor. The low-pulsatile state increases muscle sympathetic nerve activity via a baroreceptor-mediated pathway and elevates angiogenic factors, which leads to increased vascular stiffness and microvascular dysfunction. Activation of systemic inflammation increases the level of C-reactive protein and acts as a prothrombotic. Finally, mechanical interaction between the left ventricle and the device as well as permanent antithrombotic and antiplatelet therapy may lead to haemorrhagic and thrombotic complications, including pump thrombosis [11].

\section{Bleeding}

Bleeding occurs mainly in the early postoperative period and is associated with an increased number of repeated thoracotomy and blood transfusions. During follow-up, gastrointestinal bleeding $(\mathrm{GIB})$ is the most frequent complication, with an incidence varying from $12 \%$ to $40 \%$, depending on the device type and reporting centre. It is responsible for almost $30 \%$ of hospital readmissions [12-14]. The reason for increased GIB in patients after LVAD implantation is not known. One of the possible hypotheses is mechanical destruction, and subsequent deactivation, of the multimer of von Willebrand factor $[15,16]$. The other possible causes of GIB are arteriovenous malformations, which are thought to be caused by continuous flow and loss of pulsatility $[17,18]$. The use of a third-generation HeartMate 3 device, however, did not show a decrease in GIB despite increased pulsatility of generated flow [13]. Additionally, anticoagulant and antiplatelet therapy play an important role in the increased risk of bleeding [19].

\section{Driveline infections}

Device-associated infections are responsible for more than $20 \%$ of readmissions. The infection mostly affects the skin and subcutaneous tissue close to the driveline, but it can expand and develop into a systemic infection. The prevalence of drive-line infections varied from $13 \%$ to $28 \%$, depending on the device type and analysed cohort [20]. In the Momentum 3 trial cohort, driveline infection was observed in $23.8 \%$ of patients with HeartMate 3 devices, whereas sepsis was seen in $13.8 \%$ of patients during two years of follow-up [13].

\section{Right heart failure}

The rate of RHF is high among patients after LVAD implantation and concerns $10 \%$ to $30 \%$ of patients, according to the latest reports [21]. The incidence of RHF varies between centres, depending on the patient profile, indication for LVAD implantation, and the definition of RHF used [22, 23]. The occurrence of RHF is significantly higher during the early postoperative period, but RHF can appear at any time after the implantation. Early RHF can be treated medically as well 
as with the use of temporary mechanical right ventricular (RV) support. Lack of improvement in RV function on temporary support or medical therapy requires additional implantation of long-term support devices [24]. Independently of the type of device used, the long-term mortality in patients with biventricular support is higher as compared to patients with LVAD only. There have been many attempts to predict RHF after implantation of LVAD. In spite of the efforts of many studies, introduction of different risk scores, and identification of haemodynamic as well as echocardiographic parameters, the reported incidence of RHF remains high and is associated with increased mortality. RHF is a complex clinical issue with many different factors influencing the RV function after LVAD implantation. The RV may be altered in many ways, leading to RHF. Preoperative factors, such as RV systolic performance, liver and kidney function, and signs of multi-organ failure, define the future RV function. In patients with lower INTERMACS class RHF occurs significantly more frequently. During operation, the function of the RV can be affected by many intraoperative factors, such as air embolism or volume overload. In the postoperative period, many factors can affect the RV, such as bleeding or insufficient afterload reduction. Identifying the right time for LVAD implantation, before the irreversible injury of the RV occurs, is the most important factor in preventing RHF after LVAD implantation.

\section{Device thrombosis}

Device thrombosis (DTh) is one of the most serious complications following LVAD implantation. The incidence of DTh increases systematically along with the time of support, affecting about $20 \%$ of patients after two years [25]. The risk of DTh is highest during the first six months after implantation, then it remains stable for the subsequent years [26]. In a series of 9808 patients in whom a HeartMate II device was implanted between the years 2008 and 2014, 995 events of pump thrombosis were identified and 912 pump exchanges were performed. The rates of freedom from DTh were $93 \%$ after 12 months and $89 \%$ after 24 months of support. The main recognised risk factors of DTh include: younger age, female sex, white race, larger body mass index (BMI), RHF, blood group other than 0 , malposition of the cannula, suction events, and history of noncompliance [26, 27]. In in the HeartWare BTT trial, a thrombosis rate of $8.1 \%$ or 0.08 EPPY was reported [28]. The diagnosis of DTh is difficult — the clinical symptoms of HF together with laboratory signs of haemolysis should raise the suspicion. The evaluation of log-files showing increased energy consumption and specific echocardiographic findings make it possible to establish a diagnosis in most cases $[29,30]$. In selected cases computed tomography can be very useful, especially for the detection of thrombus [31].

Pump thrombosis is a critical disease requiring immediate therapy. The treatment options include medical or surgical therapy and partly depend on the device type. In HeartMate II patients, device exchange is the standard treatment performed, with relatively low operative risk. Better survival as well as fewer cerebrovascular events were observed in patients after pump exchange as compared to medically treated patients [32]. Comparison of late outcomes of patients after pump exchange showed decreased survival as compared to patients without pump thrombosis and exchange [5]. The medical treatment of pump thrombosis generally consists of antithrombotic or thrombolytic therapy. Thrombolysis was found to be more effective in patients after HeartWare implantation and can be used in the case of thrombosis, however, pump exchange can also be performed. In selected cases, when the organ allocation system allows, heart transplantation is a good treatment option [33].

\section{Device malfunction}

Device malfunction is a relatively rare complication involving mechanical problems of the device, damage caused by device flooding, or mechanical damage of the power supply cable or controller. The risk remains constant during follow-up.

\section{RIGHT VENTRICULAR ASSIST DEVICES}

Currently, only pulsatile extracorporeal pumps such as Excor (BerlinHeart) and POLVAD-MEV (Zabrze, Poland) are dedicated to RV support. However, they are used as BiVAD, simultaneously supporting the left ventricle. Long-term, isolated RV support is not routinely performed. Continuous-flow assist devices are not used to support the RV except for very special cases, practically only for biventricular support [34]. The specific anatomy of the RV, increased trabeculation, the presence of papillary muscle, and finally relatively thin RV wall make the placement of the device challenging. Additionally, lower pressure and vascular resistance in the pulmonary circulation lead to increased flow generated by the pump at a normal speed [35]. For these reasons, the use of LVAD as RV support RVAD is limited and not suitable for separate, long-term RV support. Short-term devices such as CentriMag (Abbott) or Impella RP (Abiomed Inc.) can be effectively used for temporary RV support.

\section{BIVENTRICULAR ASSIST DEVICE}

The classic BiVAD system, Excor (the only available device for adults, children, and newborns), and the POLVAD-MEV device consist of two separate chambers for the left and right ventricles. Each chamber has two compartments separated by an elastic membrane, one containing blood and the other containing air. Increasing air pressure moves the blood out of the chamber, which imitates systole. A decrease of the air pressure in the chamber causes suction of the blood into the chamber, which imitates diastole. Two venous cannulas lead the blood from the right and left atria into the pump, whereas two atrial cannulas lead the blood driven by the compressed air from the pump into the aorta and pulmonary 


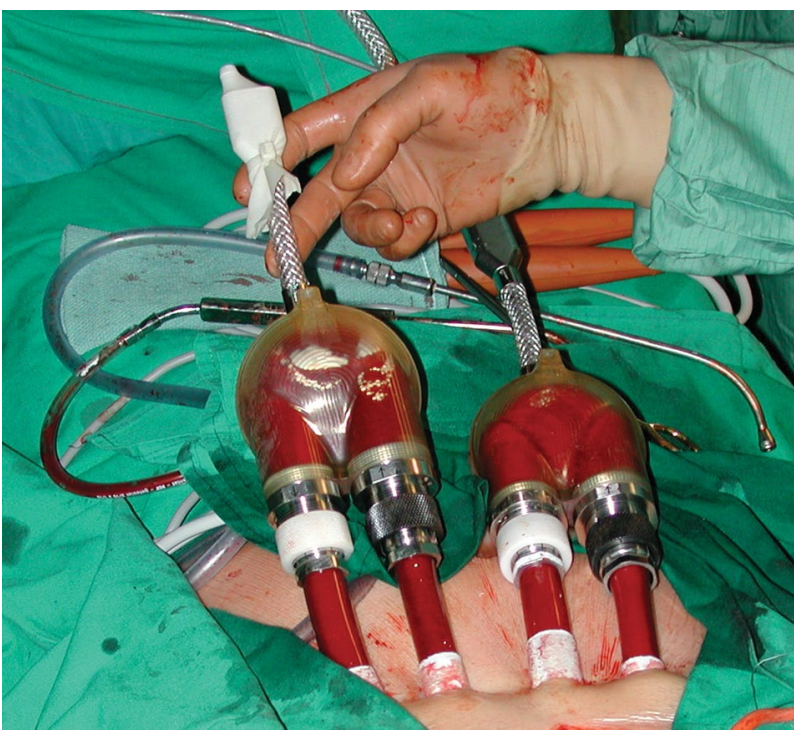

Figure 5. Pneumatic driven pulsatile biventricular device

trunk. The system generates pulsatile flow (Fig. 5). Although many patients with advanced chronic HF who are eligible for a mechanical support strategy can be managed with isolated LVADs, some of those suffering from concomitant RHF may require biventricular support as a primary treatment strategy. While the number of LVAD implantations is constantly growing, the number of implanted BiVADs remains constant worldwide. According to the eighth INTERMACS report, BiVAD (both pulsatile and continuous-flow) implantations account for $5 \%$ of all ventricular assist device implantations, including the TAH [5].

\section{PATIENT PROFILE AND INDICATIONS FOR IMPLANTATION}

The clinical profile of patients referred for LVAD or BiVAD implantation varies considerably. In general, the BiVAD recipients belong to a lower INTERMACS class and are more severely ill than LVAD recipients. They present with lower cardiac index, higher pulmonary capillary wedge pressure, and higher levels of total bilirubin and creatinine. BiVAD recipients more often required intra-aortic balloon pump and mechanical ventilation before support. The main indications for early biventricular support are acute circulatory collapse due to fulminant myocarditis, acute decompensation of dilated cardiomyopathy, massive myocardial infarction, and acute deterioration following toxic cardiomyopathy. In addition to biventricular failure, BiVAD support may be more suitable in the presence of other cardiac pathologies such as infiltrative cardiomyopathy, restrictive cardiomyopathy, and other cardiac malignancies that may be contraindicative to isolated LVAD support [9]. The main indications for BiVAD implantation are listed in Table 4. The preoperative assessment of RV function using invasive and noninvasive measurements
Table 4. Indications for biventricular mechanical support. Adapted from [46]

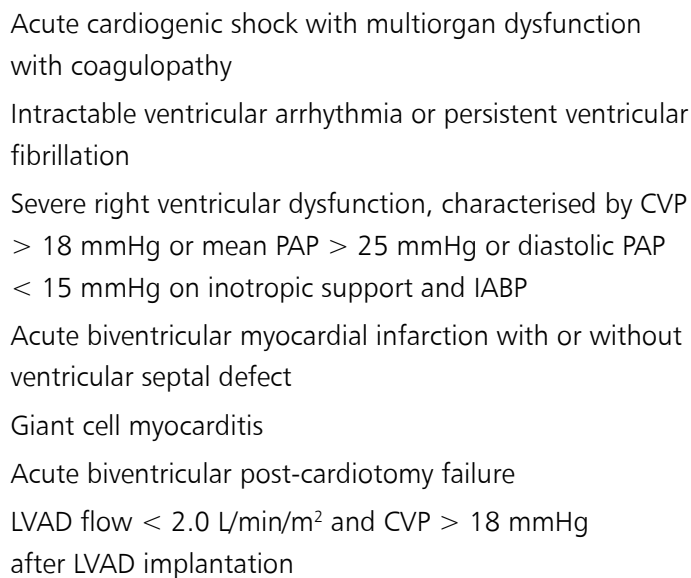

CVP — central venous pressure; IABP — intra-aortic balloon pump LVAD — left ventricular assist device; PAP — pulmonary artery pressure

is mandatory. In the process of choosing between LVAD and BiVAD implantation, it appears more reliable to use complex quantitative scoring systems that incorporate measures of different risk factors for post-LVAD RHF and composite variables that include RV geometry, function, and load. In addition to these composite variables, the scoring systems (using weighted scales) incorporating preoperative laboratory measurements, clinical data, and haemodynamic measurements, have been shown to better predict RV failure and thus became particularly useful in decision-making before BiVAD implantation. The most commonly used scoring systems are the Michigan score with different modifications, the CRITT score, and the total RHF score for the need for BiVAD [23, 36-38].

\section{STRATEGIES FOR BIVENTRICULAR CIRCULATORY SUPPORT}

Two systems of pulsatile extracorporeal pumps, Excor and POLVAD-MEV, are the most widely utilised for permanent biventricular support [39]. However, other systems can also be used for this purpose. Instead of a pulsatile pump, continuous-flow systems such as HeartWare or HeartMate can be incorporated separately for left and right ventricular mechanical support in an off-label manner [40]. In the case of RHF occurring after the implantation of LVAD, combined use of continuous-flow LVAD and pulsatile RV support could also be a solution. In the short-term, a magnetically levitated paracorporeal centrifugal pump can be utilised, such as the CentriMag, which can be used for left, right, and biventricular support. It requires surgical implantation by sternotomy but it provides full circulatory support and complete cardiac unloading. Maximal flow is $10 \mathrm{~L} / \mathrm{min}$ and duration of support is intended for up to 30 days, but longer use has also been reported. Anticoagulation with intravenous heparin is obligatory. 


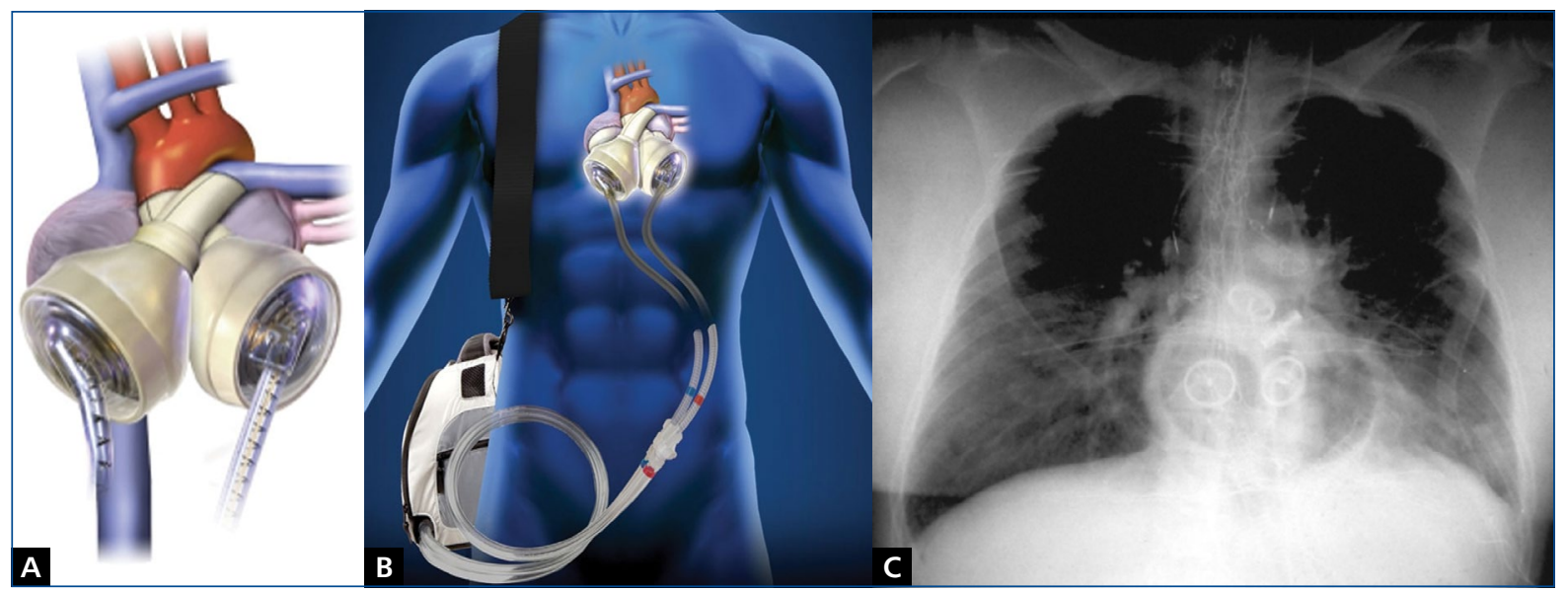

Figure 6. Graphic presentation of the SynCardia total artificial heart (TAH). A. Schematic presentation of implanted TAH. Please note that both ventricles are replaced with pneumatically driven ventricles. The high-pressure lines and anastomosis of TAH cannulas with ascending aorta and pulmonary trunk can be seen; B. Graphic presentation of implanted TAH with pressure lines and Freedom Portable Driver that delivers the compressed air to drive the pump; C. Chest X-ray of a patient after the SynCardia TAH implantation. Note the presence of four mechanical prostheses of the TAH (https://syncardia.com/clinicians/media/image-gallery/)

It can be weaned over several weeks, and, depending on the implantation technology (a Hemashield prothesis tunnelled to the skin), removal is feasible without sternotomy.

\section{SURVIVAL AFTER BIVENTRICULAR SUPPORT}

Patients with BiVAD support demonstrated consistently lower four-year survival in comparison to LVAD recipients, regardless of the support mode (continuous vs. pulsatile flow) and time of analysis [4, 41]. Moreover, the survival of patients awaiting heart transplantation while being on BiVAD has been reported to be significantly lower in comparison to patients bridging to heart transplantation on LVAD [42]. On the other hand, survival while on support and after heart transplantation did not differ significantly in patients supported with paracorporeal BiVADs, implantable BiVADs, or TAH. Patients undergoing prolonged (> 90 days) support, however, tended to have improved survival when supported with TAH compared with BiVADs, which may be related to a lower incidence of neurological events. Patients receiving RVAD several days after LVAD had much worse outcome than those who received the RVAD and LVAD simultaneously. Based on the United Network for Organ Sharing registry data and the INTERMACS registry reports, it is clear that BiVAD and TAH patients have worse early to mid-term outcomes in comparison to LVAD recipients, even when bridged to transplantation $[4,5]$. This study determined the independent predictors of lower five-year survival in the BiVAD cohort, which included age over 60 years, increasing liver failure, BMI above $30 \mathrm{~kg} / \mathrm{m}^{2}$, and intensive care unit stay before transplantation.

Despite all the limitations of pulsatile paracorporeal assist devices, both the Excor and the POLVAD-MEV systems are still in use. These are excellent and highly versatile devices for the mid- and long-term support of patients of all ages and with different types of underlying heart disease. One of the advantages of these systems is the possibility of visual inspections of intracannular thrombi, which facilitates monitoring of antithrombic therapy. Moreover, the Excor pump offers variable pump sizes, ranging from 10 to $60 \mathrm{~mL}$. The implant procedure and the perioperative management of these pulsatile devices are relatively simple, with low complication rates when managed by experienced cardiac surgery/mechanical support centres [39, 43, 44].

\section{TOTAL ARTIFICIAL HEART}

Total artificial heart is an implantable device designated for long-term, complete circulatory support. Nowadays the SynCardia TAH (SynCardia Systems) is the only one available on the market. It is a pneumatically driven pulsatile device, similar to the Excor biventricular device. In contrast to the Excor system, TAH is completely implanted in the patient (Fig. 6A-C). The indication for implantation is the lack of eligibility for the use of LVAD or BiVAD due to the most extreme heart pathologies, such as extensive heart infarction, especially with concomitant postinfarction ventricular septal defect, large intracardiac thrombus, extensive coronary artery dissection, or cardiac tumours. TAH is principally implanted as bridge to transplantation only. The number of implantations is far lower than for LVAD - 226 patients as compared with 10,726 persons implanted with LVAD between 2013 and 2016. Survival rates after 12 and 24 months of support were $52 \%$ and $37 \%$, respectively [5]. In spite of relatively low survival rates, TAH is an irreplaceable system allowing bridging of patients with extreme cardiac pathologies. The Carmat TAH has been successfully tested in France, Prague, and Astana. 


\section{CONCLUSIONS}

The problems related to LVAD use are not limited to numerous surgical and medical complications. Relatively high costs and the need for experienced cardiac surgery centres should not be underestimated either. However, the most important issue is to develop a complex system providing care of MCS patients throughout the treatment process. The implantation centre must have the possibility to hospitalise the patient at any time. Well-trained, specialised nursing personnel able to take care of both the patient and the device (VAD coordinators), accessible $24 \mathrm{~h}$ a day, is necessary. A team of psychologists that could offer support to the patient and their family should be available in every VAD centre. The family of the patient and his/her general practitioner have to be trained and ready to provide qualified help, including daily control of anticoagulation treatment. Finally, palliative care, an extremely important part of the treatment of end-stage HF, must be provided correspondingly in ambulatory form.

The number of implanted mechanical support systems is growing constantly, with LVADs being the most commonly used. In Poland, between the years 2012 and 2017, 229 LVAD systems, mostly HeartMate 3 and HeartWare pumps, have been implanted. This trend will continue in the future as the number of patients suffering from HF increases, and there are no rational reasons for assuming that the number of heart transplants will increase. The use of LVADs seems to be the only solution for patients with isolated left ventricular failure. The short- and long-term survival rates, in spite of many complications, are much better than for medical treatment. The use of MCS remains far beyond medical experiment. It is an established treatment option for many patients, which, unfortunately, will not be provided in many countries because of organisational and reimbursement problems. Nevertheless, the most important issue for cardiologists is to identify patients eligible for MCS, in order to give them a chance for a longer life and better quality of life.

Conflict of interest: Michał Zembala - consultant for Boston Scientific; other authors declare no conflict of interest.

\section{References}

1. Maggioni AP, Dahlström U, Filippatos G, et al. Heart Failure Association of the European Society of Cardiology (HFA). EURObservational Research Programme: regional differences and 1-year follow-up results of the Heart Failure Pilot Survey (ESC-HF Pilot). Eur J Heart Fail. 2013; 15(7): 808-817, doi: 10.1093/eurjhf/hft050, indexed in Pubmed: 23537547.

2. Ponikowski P, Voors A, Anker S, et al. 2016 ESC Guidelines for the Diagnosis and Treatment of Acute and Chronic Heart Failure. Rev Esp Cardiol (Engl Ed). 2016; 69(12): 1167, doi: 10.1016/j. rec.2016.11.005

3. Zembala MO, Antonczyk R, Niklewski T, et al. Simplified, less-invasive left ventricular assist device implantation in patients with post-coronary artery bypass grafting. Interact Cardiovasc Thorac Surg. 2018 [Epub ahead of print], doi: 10.1093/icvts/ivy250, indexed in Pubmed: 30239891.

4. Kirklin JK, Naftel DC, Pagani FD, et al. Seventh INTERMACS annual report: 15,000 patients and counting. J Heart
Lung Transplant. 2015; 34(12): 1495-1504, doi: 10.1016/j. healun.2015.10.003, indexed in Pubmed: 26520247.

5. Kirklin JK, Pagani FD, Kormos RL, et al. Eighth annual INTERMACS report: Special focus on framing the impact of adverse events. J Heart Lung Transplant. 2017; 36(10): 1080-1086, doi: 10.1016/j.healun.2017.07.005, indexed in Pubmed: 28942782.

6. Krabatsch T, Netuka I, Schmitto JD, et al. Heartmate 3 fully magnetically levitated left ventricular assist device for the treatment of advanced heart failure - 1 year results from the Ce mark trial. J Cardiothorac Surg. 2017; 12(1): 23, doi: 10.1186/s13019-0170587-3, indexed in Pubmed: 28376837.

7. Cho SM, Moazami N, Frontera JA. Stroke and intracranial hemorrhage in heartmate II and heartware left ventricular assist devices: a systematic review. Neurocrit Care. 2017; 27(1): 17-25, doi: 10.1007/s12028-017-0386-7, indexed in Pubmed: 28324260.

8. Slaughter MS, Rogers JG, Milano CA, et al. Advanced heart failure treated with continuous-flow left ventricular assist device. NEngl J Med. 2009; 361(23): 2241-2251, doi: 10.1056/NEJMoa0909938, indexed in Pubmed: 19920051.

9. Slaughter MS, Pagani FD, McGee EC, et al. HeartWare ventricular assist system for bridge to transplant: combined results of the bridge to transplant and continued access protocol trial. J Heart Lung Transplant. 2013; 32(7): 675-683, doi: 10.1016/j. healun.2013.04.004, indexed in Pubmed: 23796152.

10. Acharya D, Loyaga-Rendon R, Morgan CJ, et al. INTERMACS analysis of stroke during support with continuous-flow left ventricular assist devices: risk factors and outcomes. JACC Heart Fail. 2017; 5(10): 703-711, doi: 10.1016/j.jchf.2017.06.014, indexed in Pubmed: 28958345.

11. Mehra MR. The burden of haemocompatibility with left ventricular assist systems: a complex weave. Eur Heart J. 2017 [Epub ahead of print], doi:10.1093/eurheartj/ehx036, indexed in Pubmed: 28329374.

12. Hasin T, Marmor Y, Kremers W, et al. Readmissions after implantation of axial flow left ventricular assist device. J Am Coll Cardiol. 2013; 61(2): 153-163, doi: 10.1016/j.jacc.2012.09.041, indexed in Pubmed: 23219299.

13. Mehra MR, Goldstein DJ, Uriel N, et al. Two-Year outcomes with a magnetically levitated cardiac pump in heart failure. $\mathrm{N}$ Engl J Med. 2018; 378(15): 1386-1395, doi: 10.1056/NEJMoa1800866, indexed in Pubmed: 29526139.

14. Rogers JG, Pagani FD, Tatooles AJ, et al. Intrapericardial left ventricular assist device for advanced heart failure. N Engl J Med. 2017; 376(5): 451-460, doi: 10.1056/NEJMoa1602954, indexed in Pubmed: 28146651.

15. Uriel N, Pak SW, Jorde UP, et al. Acquired von Willebrand syndrome after continuous-flow mechanical device support contributes to a high prevalence of bleeding during long-term support and at the time of transplantation. J Am Coll Cardiol. 2010; 56(15): 1207-1213, doi: 10.1016/j.jacc.2010.05.016, indexed in Pubmed: 20598466.

16. Imamura T, Kinugawa K, Uriel N. Therapeutic strategy for gastrointestinal bleeding in patients with left ventricular assist device. Circ J. 2018; 82(12): 2931-2938, doi: 10.1253/circj.CJ-18-0883, indexed in Pubmed: 30369592.

17. Demirozu ZT, Radovancevic R, Hochman LF, et al. Arteriovenous malformation and gastrointestinal bleeding in patients with the HeartMate II left ventricular assist device. J Heart Lung Transplant. 2011; 30(8): 849-853, doi: 10.1016/j.healun.2011.03.008, indexed in Pubmed: 21530318.

18. Harvey L, Holley CT, John R. Gastrointestinal bleed after left ventricular assist device implantation: incidence, management, and prevention. Ann Cardiothorac Surg. 2014; 3(5): 475-479, doi: 10.3978/j.issn.2225-319X.2014.08.19, indexed in Pubmed: 25452907.

19. Molina TL, Krisl JC, Donahue KR, et al. Gastrointestinal bleeding in left ventricular assist device: octreotide and other 
treatment modalities. ASAIO J. 2018; 64(4): 433-439, doi: 10.1097/MAT.0000000000000758, indexed in Pubmed: 29406356.

20. Schaffer J, Allen J, Weiss E, et al. Infectious complications after pulsatile-flow and continuous-flow left ventricular assist device implantation. J Heart Lung Transplant. 2011; 30(2): 164-174, doi: 10.1016/j.healun.2010.08.003.

21. Patlolla B, Beygui R, Haddad F. Right-ventricular failure following left ventricle assist device implantation. Curr Opin Cardiol. 2013; 28(2): 223-233, doi:10.1097/HCO.0b013e32835dd12c, indexed in Pubmed: 23337895.

22. Drakos SG, Janicki L, Horne BD, et al. Risk factors predictive of right ventricular failure after left ventricular assist device implantation. Am J Cardiol. 2010; 105(7): 1030-1035, doi: 10.1016/j. amjcard.2009.11.026, indexed in Pubmed: 20346326.

23. Fitzpatrick JR, Frederick JR, Hsu VM, et al. Risk score derived from pre-operative data analysis predicts the need for biventricular mechanical circulatory support. J Heart Lung Transplant. 2008; 27(12): 1286-1292, doi: 10.1016/j.healun.2008.09.006, indexed in Pubmed: 19059108.

24. Takeda K, Naka Y, Yang JA, et al. Timing of temporary right ventricular assist device insertion for severe right heart failure after left ventricular assist device implantation. ASAIO J. 2013; 59(6): 564-569, doi: 10.1097/MAT.0b013e3182a816d1, indexed in Pubmed: 24088902.

25. Stulak JM, Davis ME, Haglund N, et al. Adverse events in contemporary continuous-flow left ventricular assist devices: A multi-institutional comparison shows significant differences. J Thorac Cardiovasc Surg. 2016; 151(1): 177-189, doi: 10.1016/j. jtcvs.2015.09.100, indexed in Pubmed: 26545967.

26. Kirklin JK, Naftel DC, Pagani FD, et al. Pump thrombosis in the Thoratec HeartMate II device: An update analysis of the INTERMACS Registry. J Heart Lung Transplant. 2015; 34(12): 1515-1526, doi: 10.1016/j.healun.2015.10.024, indexed in Pubmed: 26681121.

27. Kirklin JK, Naftel DC, Kormos RL, et al. Interagency Registry for Mechanically Assisted Circulatory Support (INTERMACS) analysis of pump thrombosis in the HeartMate II left ventricular assist device. J Heart Lung Transplant. 2014; 33(1): 12-22, doi: 10.1016/j.healun.2013.11.001, indexed in Pubmed: 24418730.

28. Najjar SS, Slaughter MS, Pagani FD, et al. An analysis of pump thrombus events in patients in the HeartWare ADVANCE bridge to transplant and continued access protocol trial. J Heart Lung Transplant. 2014; 33(1): 23-34, doi: 10.1016/j. healun.2013.12.001, indexed in Pubmed: 24418731.

29. Stainback RF, Estep JD, Agler DA, et al. Echocardiography in the management of patients with left ventricular assist devices: recommendations from the American Society of Echocardiography. J Am Soc Echocardiogr. 2015; 28(8): 853-909, doi: 10.1016/j. echo.2015.05.008, indexed in Pubmed: 26239899.

30. Paluszkiewicz L, Gürsoy D, Spiliopoulos S, et al. HeartMate II ventricular assist device thrombosis-an echocardiographic approach to diagnosis: can Doppler evaluation of flow be useful? J Am Soc Echocardiogr. 2011; 24(3): 350.e1-350.e4, doi: 10.1016/j. echo.2010.06.007, indexed in Pubmed: 20656454.

31. Tran BC, Nijjar PS. Role of contrast CT for the diagnosis and the prognosis of suspected LVAD thrombosis. J Card Surg. 2017; 32(2): 162-165, doi: 10.1111/jocs.13094, indexed in Pubmed: 28088844 .

32. Levin AP, Saeed O, Willey JZ, et al. Watchful waiting in continuous-flow left ventricular assist device patients with ongoing hemolysis is associated with an increased risk for cerebrovascular accident or death. Circ Heart Fail. 2016; 9(5), doi: 10.1161/CIRCHEARTFAILURE.115.002896, indexed in Pubmed: 27166248.

33. Nguyen AB, Uriel N, Adatya S. New challenges in the treatment of patients with left ventricular support: LVAD thrombosis. Curr
Heart Fail Rep. 2016; 13(6): 302-309, doi: 10.1007/s11897-0160310-z, indexed in Pubmed: 27878511.

34. Shehab S, Macdonald PS, Keogh AM, et al. Long-term biventricular HeartWare ventricular assist device support. Case series of right atrial and right ventricular implantation outcomes. J Heart Lung Transplant. 2016; 35(4): 466-473, doi: 10.1016/j. healun.2015.12.001, indexed in Pubmed: 26849954.

35. Karimov JH, Sunagawa G, Horvath D, et al. Limitations to chronic right ventricular assist device support. Ann Thorac Surg. 2016; 102(2): 651-658, doi: 10.1016/j.athoracsur.2016.02.006, indexed in Pubmed: 27106620.

36. Shiga T, Kinugawa K, Imamura T, et al. Combination evaluation of preoperative risk indices predicts requirement of biventricular assist device. Circ J. 2012; 76(12): 2785-2791, indexed in Pubmed: 22878403.

37. Atluri P, Goldstone AB, Fairman AS, et al. Predicting right ventricular failure in the modern, continuous flow left ventricular assist device era. Ann Thorac Surg. 2013; 96(3): 857-863, doi: 10.1016/j.athoracsur.2013.03.099, indexed in Pubmed: 23791165.

38. Dandel M, Krabatsch T, Falk V. Left ventricular vs. biventricular mechanical support: Decision making and strategies for avoidance of right heart failure after left ventricular assist device implantation. Int J Cardiol. 2015; 198: 241-250, doi: 10.1016/j. ijcard.2015.06.103, indexed in Pubmed: 26232775.

39. Schmid C, Tjan T, Etz C, et al. The excor device - revival of an old system with excellent results. Thorac Cardiovasc Surg. 2006; 54(6): 393-399, doi: 10.1055/s-2006-924268, indexed in Pubmed: 16967375 .

40. Hetzer R, Krabatsch T, Stepanenko A, et al. Long-term biventricular support with the heartware implantable continuous flow pump. J Heart Lung Transplant. 2010; 29(7): 822-824, doi: 10.1016/j.healun.2010.02.012, indexed in Pubmed: 20417132.

41. Kirsch M, Mazzucotelli JP, Roussel JC, et al. Groupe de Réflexion sur l'Assistance Mécanique. Survival after biventricular mechanical circulatory support: does the type of device matter? J Heart Lung Transplant. 2012; 31(5): 501-508, doi: 10.1016/j. healun.2011.11.024, indexed in Pubmed: 22243702.

42. Farrar DJ, Hill JD, Pennington DG, et al. Preoperative and postoperative comparison of patients with univentricular and biventricular support with the thoratec ventricular assist device as a bridge to cardiac transplantation. J Thorac Cardiovasc Surg. 1997; 113(1): 202-209, doi: 10.1016/S0022-5223(97)70416-1, indexed in Pubmed: 9011691.

43. Kuśmierczyk M, Kuć M, Szymański J, et al. Pulsatile-flow mechanical circulatory support (MCS) as a bridge to transplantation or recovery. Single-centre experience with the POLCAS system in 2014. Kardiochir Torakochirurgia Pol. 2015; 12(3): 228-232, doi: 10.5114/kitp.2015.54458, indexed in Pubmed: 26702278.

44. Nadziakiewicz P, Szyguła-Jurkiewicz B, Pacholewicz J, et al. Predictive value of models for end-stage liver disease score in patients with pulsatile flow POLVAD MEV left ventricular assist device support. Transplant Proc. 2018; 50(7): 2075-2079, doi: 10.1016/j. transproceed.2018.02.160, indexed in Pubmed: 30177112.

45. Stevenson LW, Pagani FD, Young JB, et al. INTERMACS profiles of advanced heart failure: the current picture. J Heart Lung Transplant. 2009; 28(6): 535-541, doi: 10.1016/j.healun.2009.02.015, indexed in Pubmed: 19481012.

46. Tsukui H, Teuteberg JJ, Murali S, et al. Biventricular assist device utilization for patients with morbid congestive heart failure: a justifiable strategy. Circulation. 2005; 112(9 Suppl): I65-I72, doi: 10.1161/CIRCULATIONAHA.104.524934, indexed in Pubmed: 16159867.

Cite this article as: Paluszkiewicz L, Kukulski T, Zembala M, et al. The role of long-term mechanical circulatory support in the treatment of end-stage heart failure. Kardiol Pol. 2019; 77(3): 331-340, doi: 10.5603/KP.a2019.0027. 